\title{
Graduate Education in Clinical Laboratory Science Is the Glass Half Full or Half Empty?
}

\author{
KAREN KARNI, JOAN POLANCIC, JOANN FENN, DONNA J. SPANNAUS-MARTIN
}

OBJECTIVE: To evaluate the 2007 and 1990 data on the number and characteristics of programs offering graduate level degrees in Clinical Laboratory Science.

DESIGN/SETTING/PARTICIPANT: Data were collected from published sources (Directory of Graduate Programs for Clinical Laboratory Practitioners) and analyzed at the University of Minnesota. Specific data regarding the kinds of advanced programs and the number of graduates per year, the number of program openings and closures, program requirements were collected, as well as data regarding the number and employment of graduates of Master's degree programs at two long-standing public institutions.

\section{INTERVENTION: Not Applicable.}

MAIN OUTCOME MEASURE: The tabulation of degree, program, and graduate data, together with the first position taken by graduates of two M.S. programs.

RESULTS: The numbers of graduate level programs and graduates decreased between 1990 and 2007, from 39 to 28 identified Master's level programs, but with only a slight increase from two to five doctoral programs. Several prominent and historically important Master's level programs have closed since the first edition (1990) of the Directory. Detailed analysis of the data from two Master's level programs showed that the first positions for graduating students were predominantly research related and in the same state as the degree-granting institution.

CONCLUSION: The number of advanced programs and graduates are relatively small in clinical laboratory science; however M.S. graduates are successful in obtaining positions. These positions are predominantly geographically related to the degree-granting institution, indicating an intellectual and economic impact of the programs in the regions they are located.

ABBREVIATIONS: ASCLS = American Society for Clinical Laboratory Science; CLS = Clinical Laboratory Science; $\mathrm{ASMT}=$ American Society for Medical Technology; TOEFL $=$ Test of English as a Foreign Language.

INDEX TERMS: Clinical Laboratory Science; Graduate Education; Health, Manpower; Laboratory Personnel; Students, Health Occupations.

Clin Lab Sci 2010;23(3):166

Karen Karni, PhD, CLS(NCA), University of Minnesota, Program in Clinical Laboratory Sciences, Minneapolis, MN 55455

Joan Polancic, MSEd, MLS, American Society for Clinical Laboratory Science (ASCLS), Bethesda, MD 20817-1574

JoAnn Fenn, MS, MT(ASCP), Medical Laboratory Science, Department of Pathology, University of Utah School of Medicine, Salt Lake City, UT 84132

Donna Spannaus-Martin, PhD, MLS, University of Minnesota, Program in Clinical Laboratory Sciences, Minneapolis, MN 55455

Address for Correspondence: Karen Karni, PhD, CLS(NCA), Professor Emeritus, University of Minnesota, Program in Clinical Laboratory Sciences, Mayo Mail Code 711, 420 Delaware St. SE, Minneapolis, MN 55455 


\section{RESEARCH AND REPORTS}

Since 1990, the American Society for Clinical Laboratory Science (ASCLS) has published a Directory of Graduate Programs for Clinical Laboratory Practitioners to aid potential students in choosing an advanced program of study at the Master's or doctoral levels in CLS or its specialty areas. The fifth edition of the Directory was published in November 2007. With a seventeen-year record of chronicling the initiation and closing of programs, the authors looked at trends in numbers of programs, their requirements, and graduates.

$\mathrm{Li}$, et al., have evaluated career data and the perceived value of advanced CLS degrees. ${ }^{1,2}$ They surveyed M.S. and B.S. graduates and concluded that M.S. degree respondents had more managerial level positions (62\% to $36 \%$ as compared to B.S. graduates) and had authored more external publications (77\% to $33 \%)$. CLS M.S. professionals also perceived a greater career enhancement value to their advanced degree. Each group (B.S. and M.S.) stated the most important perceived benefit of having a CLS M.S. degree as "enhanced self-esteem and confidence." The highest priority of M.S. degree recipients' motivation for obtaining a CLS advanced degree was personal satisfaction. Fenn and Knight looked at the value of graduate education (Master's level) in clinical laboratory science among M.S. graduates from the University of Utah between 1969 and 1994. ${ }^{3}$ They concluded that among these graduates, who had completed a program requiring research and a thesis, the "major benefits of a graduate education are the skills gained that relate to communication through writing, ability to read and interpret scientific literature, acquisition of new technical skills, and improvement of one's ability to establish successful new technologies in the laboratory."

Unfortunately, little is known about those who have graduated with doctoral degrees in clinical laboratory science, primarily because the numbers of programs and graduates are small. There were only two doctoral programs in clinical laboratory science identified in 1990, and five Ph.D. programs in 2007.

\section{METHOD}

The authors compared the advanced programs (M.S. and Ph.D.) and numbers of graduates using the first
(1990) and fifth (2007) editions of the Directory. Each program's entry for the Directory has information that can be seen in Figure 1. In addition, graduates' information was gathered from the directors of two M.S. programs regarding the graduates' first positions taken following completion of their graduate degrees. These institutions have kept detailed records of their graduates' first employment positions. Types and locations of employment were collected for these graduates.

\section{Graduate Directory Information}

- Name of the School and Department

- Degree Title

- Level of Degree Awarded

- Program of Study, including areas of concentration

- Year Program was Established

- Numbers of Credits Required for Graduation (semester or quarter)

- $\quad$ Research Required?

- Thesis Required?

- $\quad$ Other Requirements, e.g., seminars, projects, papers

- Minimum GPA Considered for Admission ( $\mathrm{A}=4.0)$

- GRE required? Minimum Score Considered.

- If English is not the primary language, minimum TOEFL required.

- Other Prerequisites for Admission

- Enrollment Dates

- Application Deadline

- Usual Time for a Full-time Student to Complete the Degree

- Usual Time for a Part-time Student to Complete the Degree

- Tuition and Miscellaneous Fees

- Availability of Financial Aid - Full-time and Part-time Students

- Usual Number of: Full-time Students, Part-time Students, Graduates/year

- $\quad$ Research Facilities Available

- Location of School/Features of the Community

- Faculty Names, Degrees and Their Research Interests

- Strengths of the Program

- $\quad$ Recent Thesis Titles (Examples)

- Correspondence: to whom directed (Name, address, phone, fax, email)

Figure 1. Information on Each Program Listed in the Graduate Directory

\section{RESULTS}

In clinical laboratory science, there were 39 Master's programs and two doctoral programs operating in 1990. In 2007, there were 28 Master's programs and five 


\section{RESEARCH AND REPORTS}

doctoral programs. Table 1 shows the 15 master's level programs and numbers of graduates reported in both the 1990 and 2007 editions of the Directory. Table 2 provides information on the 13 of 15 Master's level programs that were started after 1990 with the number of graduates reported in 2007. Table 3 indicates the five doctoral level programs in 2007 with numbers of graduates. Table 4 shows the 19 M.S. programs that have been discontinued since 1990. Tables 5 and 6 are an overview of graduate program requirements for admission to CLS M.S. and Ph.D. degree programs. Table 7 provides information about graduates from two recognized programs, at the University of Minnesota and the University of Utah, regarding the type and location of employment obtained following graduation.

Table 1. Institutions with Master's Programs in 1990 and 2007

\begin{tabular}{lcc}
\hline & \multicolumn{3}{c}{ Usual Number of Graduates/Year } \\
Name of Institution & 1990 & 2007 \\
Andrews University (MI) & $1-2$ & $1-2$ \\
Indiana University - Indianapolis (IN) & 3 & 2 \\
Medical College of Georgia (GA) & $0-1$ & $0-2$ \\
Michigan State University (MI) CLS & $3-6$ & 6 \\
Biomedical Laboratory Option & - & 2 \\
Quinnipiac University (CT) & 19 & 24 \\
Rosalind Franklin/Finch University (IL) & 5 & $2-5$ \\
San Francisco State University (CA) & $10-12$ & 7 \\
University of Maryland - Baltimore (MD) & $2-3$ & 5 \\
University of Massachusetts - Lowell (MA) & 3 & $5-10$ \\
University of Minnesota (MN) & 5 & 4 \\
University of North Dakota (ND) & $2-4$ & 12 \\
University of Southern Mississippi (MS) & 1 & $1-3$ \\
University of Utah (UT) & 5 & 5 \\
University of Wisconsin - Milwaukee (WI) & $1-2$ & $3-4$ \\
Virginia Commonwealth University (VA) & $2-4$ & $3-5$ \\
Range for Total Number of Students & $62-75$ & $82-98$ \\
Mean Number of Students & $4-5$ & $4-5$ \\
Median Number of Students & 4 & 4 \\
& & \\
Total Number of Institutions: & 15 & \\
Note: Only 15 of 39 institutions identified in 1990 reported offering \\
programs in 2007.
\end{tabular}

\section{DISCUSSION}

The number of clinical laboratory science Master's level programs has decreased over a 17 -year period, from 39 in 1990 to 28 in 2007. Over the same time period, the number of doctoral programs increased only slightly from two to five. The total numbers of graduates from both levels of advanced programs are relatively small, averaging four to five M.S. graduates per program per

Table 2. New Master's Level Programs Identified Between 1990 and 2007

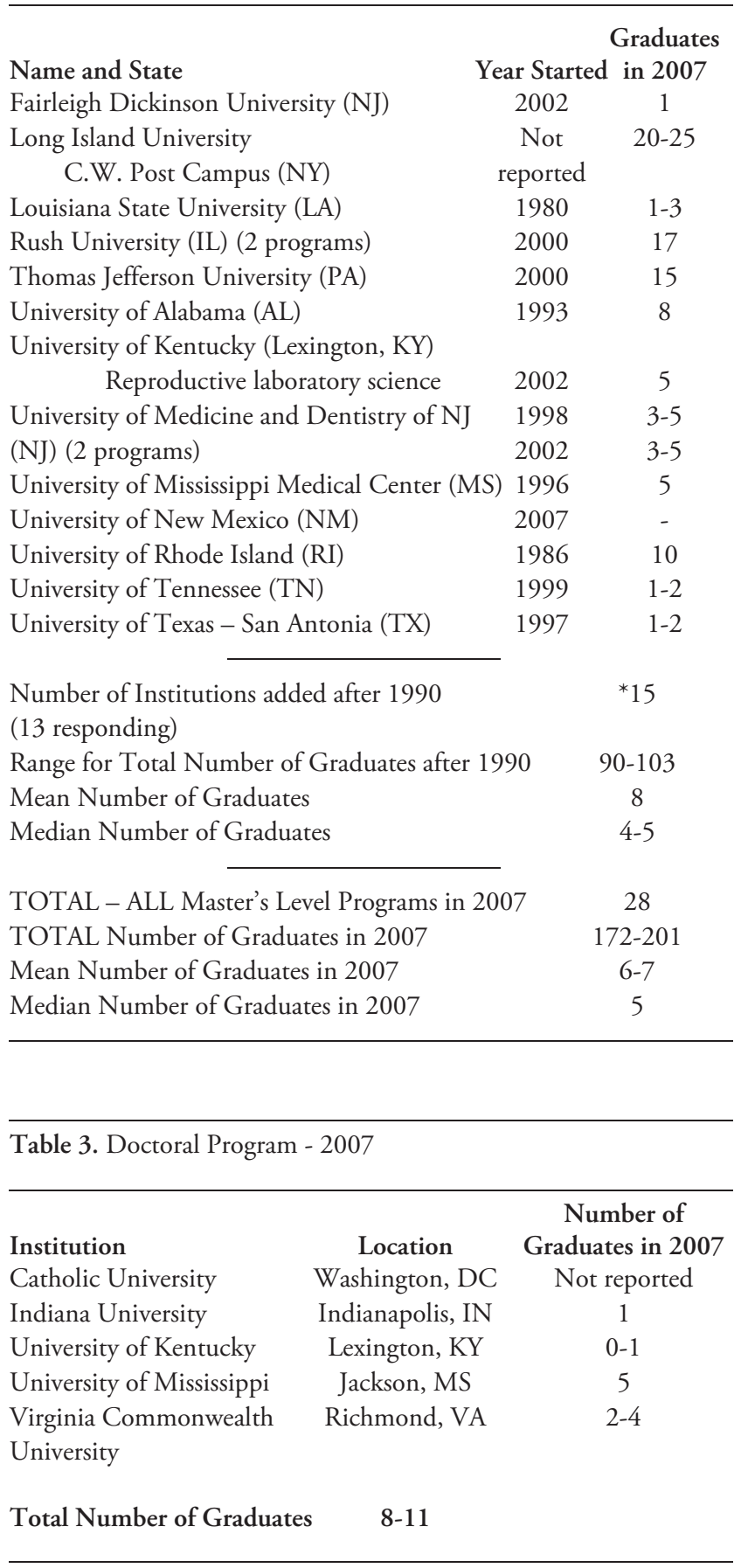

year in both 1990 and 2007. The total numbers of doctoral graduates in 2007 were 11 or fewer. 


\section{RESEARCH AND REPORTS}

It appears that not many laboratory science practitioners are pursuing advanced degrees within the profession. While some may be enrolled in other kinds of advanced level programs (MBA, education, public health, the basic or clinical sciences) or in other professional programs such as medicine, dentistry, pharmacy or law, the numbers staying within clinical laboratory science and earning the M.S. or doctoral degree remain modest. This is a matter of concern. $\mathrm{Li}$ et al. ${ }^{1,2}$ have stated that M.S. graduates, in contrast to B.S. graduates, hold career enhancement as the major value in holding an advanced degree. Career enhancement, however, may not be sufficient to attract practitioners to pursue and complete an advanced degree in clinical laboratory science. Therefore, graduates of CLS master's or doctoral programs need to be surveyed concerning their impressions of the degrees for which they were enrolled and graduated. Baccalaureate CLS graduates who choose other kinds of advanced degrees need to be surveyed as well.

Table 4. Master's Level CLS Programs That Have Closed Since 1990.

\begin{tabular}{ll}
\hline Name & State \\
Brigham Young University & Utah \\
Eastern Washington University & Washington \\
Emory University & Georgia \\
Florida International University & Florida \\
George Washington University & Washington, DC \\
Georgia State University & Georgia \\
Medical University of South Carolina & South Carolina \\
Northeastern University & Massachusetts \\
Old Dominion University & Virginia \\
Oregon Health Sciences University & Oregon \\
St. John's University & New York \\
University of Illinois & Illinois \\
University of New York - Buffalo & New York \\
University of New York - Syracuse & New York \\
University of Vermont & Vermont \\
University of Wisconsin - Eau Claire & Wisconsin \\
Wayne State University & Michigan \\
West Virginia University & West Virginia \\
Wichita State University & Kansas \\
Number of Institutions Closed & \\
Note: Four programs that were identified in & 1990 did not respond to \\
information for the 2007 Directory: Stanford University, the University of \\
Alberta, Edmonton, Canada, Inter American University of Puerto Rico, San \\
Juan, and University of Puerto Rico, San Juan. & \\
\hline
\end{tabular}

In contrast, ASCLS (ASMT at that time) and Central Michigan University co-sponsored a Master's level external degree program in either administration or

Table 5. Overview of Master's Level Graduate Program Requirements in CLS - 2007

$\begin{array}{lcc}\text { Category } & \text { Requirement } & \text { No. of Programs } \\ \text { Minimum grade point average } & 3.2 & 1 \\ & 3.0 & 18 \\ & 2.8 & 1 \\ & 2.75 & 4 \\ & 2.7 & 2 \\ \text { Graduate Record Examination } & 2.5 & 3 \\ \text { Required } & \text { Yes } & 17 \\ & \text { No } & 8 \\ & \text { International only } & 1 \\ \text { TOEFL Required } & \text { Recommended } & 1 \\ & & \\ & \text { Yes } & 24 \\ & \text { No } & 2 \\ & \text { NR } & 2\end{array}$

Semester Credits Required for Graduation (not entry level) 51

\begin{tabular}{|c|c|c|}
\hline & 39 & 1 \\
\hline & 37 & 2 \\
\hline & 36 & 9 \\
\hline & 33 & 3 \\
\hline & 32 & 2 \\
\hline & 31 & 1 \\
\hline & 30 & 7 \\
\hline & 27 & 1 \\
\hline & 23 & 1 \\
\hline Thesis Required & Yes & 11 \\
\hline & No & 10 \\
\hline & Optional & 7 \\
\hline Time for Completion (full time) & 1 calendar year & 1 \\
\hline & 2 years & 19 \\
\hline & 2.5 years & 1 \\
\hline & $2-3$ years & 1 \\
\hline & 2-6 years & 1 \\
\hline & 18 months & 1 \\
\hline & $15-18$ months & 2 \\
\hline & 3 semesters & 1 \\
\hline & 3-6 semesters & 1 \\
\hline & NR & 1 \\
\hline
\end{tabular}

From the Directory of Graduate Programs for Clinical Laboratory Practitioners, 5th Edition. Bethesda, MD; American Society for Clinical laboratory Science, November 2007. The notation NR indicates no response or unable to interpret. Data does not include two programs that did not respond to the survey. 


\section{RESEARCH AND REPORTS}

education from 1973 to $1979 .{ }^{4}$ During that time, 2,000 allied health practitioners were enrolled, with the vast majority being laboratorians. Their reasons for pursuing the M.S. degree were: 1) personal satisfaction; 2) an impetus for greater job security, increased income and new responsibilities; and 3) an increase in job-related skills. For graduates of the ASMT-CMU program, the most important benefit was increased personal confidence.

Table 6. Doctoral Program Requirements in CLS - 2007

\begin{tabular}{lcc}
\hline Minimum grade point average & 3.3 & 1 \\
& $2.75-3.0$ & 1 \\
& 3.0 & 3 \\
Graduate Record Exam required & Yes & 5 \\
TOEFL required & Yes (4) & \\
& NR (1) & 625 \\
& 1 & \\
& $600^{*}(250)$ & 2 \\
Thesis required? & $550^{*}(213)$ & 1 \\
& Yes & 4 \\
Usual time for completion & Dissertation or 3 & 1 \\
(full time) & published articles & \\
& $4-5$ years & 1 \\
& 4 years & 3 \\
$*$ computer version & $2-6$ years & 1 \\
& & \\
\hline
\end{tabular}

Note, however, the ASMT-CMU Master's degrees were in education or administration. The institutions surveyed in the five iterations of the Directory offer degrees that are primarily clinical laboratory science and research oriented. Comparisons suggest that, at least in the mid-1970s, practitioners: 1) were more interested in administration or education degrees; 2) preferred the courses in a non-traditional delivery model; and 3) perhaps had more opportunities in these areas. Today it is unknown whether and how many current laboratory practitioners are enrolled in education or administration programs and whether in traditional or non-traditional settings. Again, additional research is needed.

Francis, et al. ${ }^{5}$ studied career progress among baccalaureate graduates from the medical technology (clinical laboratory sciences) program of the University of Minnesota. Their paper stated "those who achieved advanced degrees were 1.52 times more likely to have progressed in their career when compared with those who had no advanced degrees." Thus, there are

170 VOL 23, NO 3 SUMMER 2010 CLINICAL LABORATORY SCIENCE considerable data to suggest that completion of an advanced degree is beneficial in terms of personal satisfaction, confidence and self-esteem, as well as in career advancement.

That 19 M.S. programs closed since 1990 is alarming. The decrease may parallel the decrease in the number of CLS baccalaureate programs during the same time period (from 420 to 224). ${ }^{6}$ Nonetheless, 19 schools, with fine reputations, are no longer offering students the opportunity to gain a master's degree in the profession.

While the organizers of the Graduate Directory did not collect information regarding graduate program viability, later inquiries to administrators of closed programs did provide anecdotal information regarding the reasons for closure. Reasons included lack of institutional financial support, increased tuition, lack of resources to recruit potential students, and fewer faculty to mentor students. The decline in degree programs is also described by recent studies by Waller et al. (7). Surveying faculty in 2008, the findings in this work showed that $53 \%$ of CLS faculty had taught for 16 or more years and that $25 \%$ of the faculty were 60 years old or older, close to considering retirement from faculty status. Such turnover of faculty will impact both undergraduate and graduate level programs, and will likely be compounded by the lack of replacement faculty because of the low number of students in advanced degree programs, notably doctoral degree programs in laboratory science.

The Waller study indicated that programs average only 4.2 faculty per undergraduate program. Another study conducted in 2007 to 2008, by the Association of Schools of Allied Health Professions, provides similar information for 87 institutitions showing an average of 4.1 faculty for each CLS program. ${ }^{8}$ Comparatively, Physical Therapy programs averaged 10.1 faculty, Speech Pathology and Audiology averaged 10.2 faculty, and Occupational Therapy averaged 7.2 faculty; all at the advanced degree level. These data do suggest that programs with a higher number of faculty can be better sustained. 
Table 7A. University of Minnesota Master's Program in Clinical Laboratory Science. M.S. Graduates, Positions Taken Following Graduation \& State of First Employment

\begin{tabular}{|c|c|c|c|}
\hline Student Number & Graduation Year & First Position Following Graduation & State \\
\hline 1 & 2006 & Research Fellow, Univ of Minnesota & MN \\
\hline 2 & 2006 & Unknown, Boston & MA \\
\hline 3 & 2006 & Asst. Scientist, Univ of Minnesota & MN \\
\hline 4 & 2006 & Asst. Scientist, Univ of Minnesota & $\mathrm{MN}$ \\
\hline 5 & 2006 & Asst. Scientist, Univ of Minnesota & $\mathrm{MN}$ \\
\hline 6 & 2005 & CLS, Univ of Minnesota Med Ctr, Fairview & $\mathrm{MN}$ \\
\hline 7 & 2005 & Agricultural Specialist, Board of Animal Health & \\
\hline 8 & 2005 & CLS, Fairview - Collaborative Studies & MN \\
\hline 9 & 2004 & Med Tech Program student, Univ of Minnesota & $\mathrm{MN}$ \\
\hline 10 & 2004 & Res. Scientist, Mpls Med Res Fndn, HCMC & MN \\
\hline 11 & 2004 & Res. Assistant, Univ of Minnesota & MN \\
\hline 12 & 2004 & Sr. Res. Fellow, Univ of Minnesota & $\mathrm{MN}$ \\
\hline 13 & 2003 & Asst. Scientist, Univ of Minnesota & MN \\
\hline 14 & 2003 & Res. Assoc./Lab Mgr, Univ of Michigan & MI \\
\hline 15 & 2002 & Res. Assoc., Univ of Minnesota & $\mathrm{MN}$ \\
\hline 16 & 2002 & Student, Ph.D. Program in Genetics, Univ of Minnesota & MN \\
\hline 17 & 2002 & University of Kansas & KS \\
\hline 18 & 2002 & Jr. Scientist, Univ of Minnesota & $\mathrm{MN}$ \\
\hline 19 & 2001 & Scientist, Minnesota State Board of Health & $\mathrm{MN}$ \\
\hline 20 & 2001 & Res. Assoc., Univ of Kansas Medical Center & KS \\
\hline 21 & 2001 & Student, Ph.D. Prog - Ind. U. Purdue Univ @ Indianapolis & IN \\
\hline 22 & 2001 & Sci., Dept. Biochem, Molec Bio \& Biophysics, Univ of Minnesota & MN \\
\hline 23 & 2000 & Student, Medical School, Univ of Minnesota & MN \\
\hline 24 & 2000 & Unknown & $\mathrm{N} / \mathrm{K}$ \\
\hline 25 & 1999 & Scientist, Cancer Center, Univ of Minnesota & $\mathrm{MN}$ \\
\hline 26 & 1999 & Scientist, Dept. of Microbiology, Univ of Minnesota & $\mathrm{MN}$ \\
\hline 27 & 1999 & Scientist, Lab Med and Path, Univ of Minnesota & $\mathrm{MN}$ \\
\hline 28 & 1999 & Student, Medical School, Univ of Minnesota & $\mathrm{MN}$ \\
\hline 29 & 1999 & Student, Ph.D. Program in Biochemistry, The Ohio State Univ & $\mathrm{OH}$ \\
\hline 30 & 1999 & Faculty Member, Div of Medical Technology, Univ of Minnesota & MN \\
\hline 31 & 1998 & Student, Medical School, Univ of North Dakota & ND \\
\hline 32 & 1998 & Scientist, Neuroscience Dept., Univ of Illinois & IL \\
\hline 33 & 1998 & Scientist, Dept of Lab Med and Path, Univ of Minnesota & $\mathrm{MN}$ \\
\hline 34 & 1998 & Safety Chemist, Aveda Corporation, Twin Cities & $\mathrm{MN}$ \\
\hline 35 & 1997 & Forensic Scientist, Bureau of Criminal Apprehension, Twin Cities & $\mathrm{MN}$ \\
\hline 36 & 1997 & Post Doctoral Fellow, Univ of Minnesota & MN \\
\hline 37 & 1997 & Scientist, Allergy Dept., Univ of Minnesota & MN \\
\hline 38 & 1997 & Hematology Technical Specialist, Twin Cities Clinic & MN \\
\hline 39 & 1997 & Field Application Specialist, Li-Cor Corporation & $\mathrm{NE}$ \\
\hline 40 & 1996 & Student, MBA Program, Univ of St. Thomas, St. Paul & MN \\
\hline 41 & 1996 & Student, M.S. Program in Health Informatics, Univ of Minnesota & MN \\
\hline 42 & 1996 & Scientist, Clontech Corp., Palo Alto, CA & $\mathrm{CA}$ \\
\hline 43 & 1996 & Scientist, Laboratory Animal Veterinary Clinic, Univ of Minnesota & $\mathrm{MN}$ \\
\hline 44 & 1996 & Hematology Supervisor, Lackland AFB, Texas & $\mathrm{TX}$ \\
\hline 45 & 1996 & Biotherapeutic Spec., Alexander \& Parker Corp & $\mathrm{N} / \mathrm{K}$ \\
\hline 46 & 1996 & Asst, Scientist, Dept. of Medicine, Univ of Minnesota & MN \\
\hline 47 & 1996 & Scientist, Laboratory Animal Veterinary Clinic, Univ of Minnesota & $\mathrm{MN}$ \\
\hline 48 & 1995 & Dentist, California & $\mathrm{CA}$ \\
\hline 49 & 1995 & Student, Ph.D. Program in Public Health, Univ of Texas & $\mathrm{TX}$ \\
\hline 50 & 1995 & Student, Ph.D. Program in Pathobiology, Univ of Minnesota & MN \\
\hline 51 & 1994 & Instructor, Barry Univ, Miami, FL & FL \\
\hline 52 & 1994 & Research Associate, Stanford Univ & $\mathrm{CA}$ \\
\hline 53 & 1994 & Research Associate, Singapore, Malaysia & Malaysia \\
\hline 54 & 1994 & Student, Ph.D. Program in Pathobiology, Univ of Minnesota & MN \\
\hline
\end{tabular}

35 of 54 graduates $(64 \%)$ took their first position in Minnesota.

8 of 54 graduates $(15 \%)$ enrolled in advanced studies, e.g., medical school, a Ph.D. program. 
Table 7B. University of Utah Master's Program in Laboratory Medicine and Biomedical Science. M.S. Graduates, Positions Taken Following Graduation \& State of First Employment

\begin{tabular}{|c|c|c|c|}
\hline Student Number & Graduation Year & First Position Following Graduation & State \\
\hline 1 & 2007 & Assistant Professor, Clin Lab Sci Program & UT \\
\hline 2 & 2007 & Research Scientist, University of Utah & UT \\
\hline 3 & 2007 & Medical School & UT \\
\hline 4 & 2007 & Teaching Specialist, ARUP & UT \\
\hline 5 & 2007 & Research and Development, ARUP & UT \\
\hline 6 & 2007 & Physician’s Assistant Program & NV \\
\hline 7 & 2006 & Research Scientist, Biotechnology Company & UT \\
\hline 8 & 2006 & Research Scientist, Biotechnology Company & UT \\
\hline 9 & 2006 & Medical School & UT \\
\hline 10 & 2005 & Immunology Supervisor, ARUP & UT \\
\hline 11 & 2005 & Research and Development, ARUP & UT \\
\hline 12 & 2005 & Research and Development, ARUP & UT \\
\hline 13 & 2005 & Research and Development, ARUP & UT \\
\hline 14 & 2005 & Research and Development, ARUP & UT \\
\hline 15 & 2005 & Immunology Supervisor, ARUP & UT \\
\hline 16 & 2004 & Supervisor, biotechnology Company & UT \\
\hline 17 & 2003 & High School Science Teacher - Gifted Program & UT \\
\hline 18 & 2003 & MBA Program and Scientist, Res. Lab & UT \\
\hline 19 & 2003 & Research Scientist, ARUP Laboratories & UT \\
\hline 20 & 2002 & Medical School & VT \\
\hline 21 & 2002 & Research Scientist & $\mathrm{TN}$ \\
\hline 22 & 2002 & Research Scientist, ARUP Laboratories & UT \\
\hline 23 & 2002 & Biotechnologist and Supervisor, Myriad Genetics & UT \\
\hline 24 & 2001 & Dental School & UT \\
\hline 25 & 2001 & Scientist, Heart Transplant Lab, U of Utah & UT \\
\hline 26 & 2001 & Instructor - Weber State University & UT \\
\hline 27 & 2000 & Staff Technologist, Utah Valley Hosp. blood Bank & UT \\
\hline 28 & 2000 & Ph.D. Program in Cell Bio \& Immunol & UT \\
\hline 29 & 2000 & Biotechnologist, Myriad Genetics & UT \\
\hline 30 & 1999 & Staff Technologist, Microbiology Lab - ARUP & UT \\
\hline 31 & 1999 & Research Scientist, University of UT & UT \\
\hline 32 & 1999 & Supervisor in Microbiology, St. Marks Hospital & UT \\
\hline 33 & 1999 & Research Scientist University of Utah & UT \\
\hline 34 & 1999 & Research Scientist University of Utah & UT \\
\hline 35 & 1999 & Unknown & $\mathrm{N} / \mathrm{K}$ \\
\hline 36 & 1998 & R \& D Technologist, Stem Cell lab, U of UT & UT \\
\hline 37 & 1998 & Graduate School, MBA Program, U of UT & UT \\
\hline 38 & 1998 & Supervisor, Reagents Lab - ARUP & UT \\
\hline 39 & 1997 & Group Manager Stat Lab - ARUP & UT \\
\hline 40 & 1997 & Research Scientist, University of Utah & UT \\
\hline 41 & 1997 & Supervisor, Special Chemistry - ARUP & UT \\
\hline 42 & 1996 & Lab Manager, U.S. Army & $\mathrm{N} / \mathrm{K}$ \\
\hline 43 & 1996 & Research Scientist, University of Utah & UT \\
\hline 44 & 1996 & Scientist, USAF Research Lab & MS \\
\hline 45 & 1996 & Supervisor/Micro Research Scientist Primary Children's Medical Center & UT \\
\hline 46 & 1996 & Ph.D. Program, Canada & CAN \\
\hline 47 & 1996 & Staff Technologist, Immunoheme Lab - ARUP & UT \\
\hline 48 & 1996 & Research Scientist, Immunoheme Lab, VAMC & UT \\
\hline 49 & 1996 & Supervisor, VAMC, Blood Bank & UT \\
\hline 50 & 1995 & Unknown & $\mathrm{N} / \mathrm{K}$ \\
\hline 51 & 1995 & Research Technologist, Univ of Utah & UT \\
\hline 52 & 1994 & Technical Supervisor - ARUP & UT \\
\hline 53 & 1994 & Unknown & $\mathrm{N} / \mathrm{K}$ \\
\hline 54 & 1994 & Research Scientist, University of Utah & UT \\
\hline 55 & 1994 & Research Scientist, University of Utah & UT \\
\hline
\end{tabular}




\section{RESEARCH AND REPORTS}

During the same time frame (1990-2007), 13 additional M.S. programs, also from highly reputed colleges and universities, have been initiated. These schools, and their administrators, have recognized the need for and value of the M.S. degree in the profession and their states. Nonetheless, the average number of new Master's programs is less than one per year.

From Table 5, one notes that entrance to an M.S. program requires a grade point average of 3.0, with the Graduate Record Examination required by the majority of all programs. For international students, a TOEFL exam is also required. Within M.S. programs, a thesis is required by 11 of the schools (39\%), and is optional at another 7 institutions.

Those considering new program implementation or curriculum revision, may find existing program criteria to be helpful. At the M.S. level, the predominant numbers are 30 and 36 for semester credits required for graduation, and the minimum TOEFL required is 550 .

Finally, time for completion of these advanced programs is comparable to other M.S. or Ph.D. programs nationwide. For the M.S. degree, full-time graduate work averages two years, and for the Ph.D. degree, four years.

Along with the data provided in Tables 1 through 6, we looked at trends from the schools responding in 2007. For example, at least five institutions now offer post baccalaureate certificate programs-California State University, Dominguez Hills; University of Kentucky; University of Massachusetts - Lowell; University of Medicine and Dentistry of New Jersey; and the University of North Dakota, e.g., with majors in medical technology, cytology, reproductive laboratory science. Six institutions have entry-level master's degree programs, including the University of Alabama, Medical College of Georgia, Rosalind Franklin University of Medicine and Science (formerly Finch University), Rush University, University of Southern Mississippi, and Thomas Jefferson University. Twelve colleges/universities have online courses, and one of these, the University of Medicine and Dentistry of New Jersey has all of its courses Web-based.
The advent of these new programs and the introduction of online courses have created programs with a different focus from traditional programs. Will Master's programs, with a research focus, remain viable? Will CLS Master's and Doctoral programs graduate sufficient numbers of individuals to fill faculty positions certain to become available in the future?

This study uses information provided from the programs described in the first and fifth editions of the Directory. We also sought to ascertain, independently, what first positions and their locations that graduates of master's level programs accepted following graduation. Two programs were able to supply this kind of data. Information about graduates from the two programs are collected in Table 7A and Table 7B. Note, both of these programs are located in public universities, are sciencebased, requiring research, a thesis, and its defense.

It is apparent that the majority of M.S. graduates of the University of Minnesota and University of Utah take first positions

- in research arenas as scientists or specialists in universities or in industry;

- as students in advanced programs - M.D. or Ph.D.; or

- as supervisors/administrators in clinical laboratories, including the military.

Perhaps those considering implementation of advanced programs may wish to use the data from Tables 7-A and 7-B. Obviously, graduates from the University of Minnesota and the University of Utah have been successful in their first positions. Administrators and graduate school committees, might also be impressed with the impact that these graduates have had on their employers and on the geographical region in which they are employed. Research by graduates has contributed to the intellectual acumen of the sponsoring institutions and to the profession.

\section{CONCLUSION}

Is the glass half-full or half-empty? The findings that new kinds of programs are being started at varying levels, that online courses are being developed, and that graduates of existing programs are successful all support the conclusion that the glass is half-full. There are 


\section{RESEARCH AND REPORTS}

concerns, however. The total number of Master's programs has decreased. There are relatively few numbers of graduates in many programs and the ranks of laboratory scientist faculty are aging. It behooves the profession, and faculty and administrators in colleges and universities to consider the implementation of additional CLS advanced programs, not only to better serve potential students and to advance the profession, but also to contribute to the viability of the region in which they reside.

\section{REFERENCES}

1. Li RC, Bigler WN, Blackwood LL, Venable C, Fenn JP, et al. CLS advanced degrees and career enhancement. Part 1 Comparison of career data. Clin Lab Sci, 1998; 11 (1) 21-7.

2. Li RC, et al. CLS advanced degrees and career enhancement. Part 2 - A comparison of perceptions. Clin Lab Sci. 1998; 11 (1) 28-34.
3. Fenn JP, Knight JA. The value of graduate education in clinical laboratory science. Lab Medicine, 1995: 26 (8), 537-41.

4. Karni, K. ASMT/CMU External degree program: An evaluation summary. Am J Med Tech, 1978, 44 (9) 913-20.

5. Francis DP, Hofherr LK, Peddecord KM, Karni KR, Krolak JM. The influence of perceived professional status on the career progression of CLS graduates. Clin Lab Sci, 2001: 14 (3) 1606.

6. National Accrediting Agency for Clinical Laboratory Science Data on program numbers (5600 N. River Road, Suite 720, Rosemont, IL 60018-5119).

7. Waller, K., Karni, K. Research and scholarship of clinical laboratory science faculty members. In press, Clin Lab Sci, 2010.

8. Institutional Profile Survey 2007-2008. Association of Schools of Allied Health Professions, 4400 Jenifer Street, NW, Suite 333, Washington, DC 20015. 